This is an informal report intended primarily for internal or limited external distribution. The opinions and conclusions stated are those of the author and may or may not be those of the laboratory.

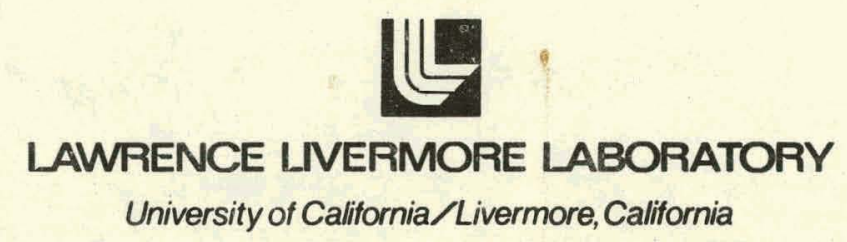

\title{
AN ANALYTIC MODEL OF CYLINDRICAL METAL LINER COMPRESSION OF DT PLASMA
}

\author{
James W. Shearer \\ June, 1974
}

\begin{abstract}
This report was $N$ T I C E
This report was prepared as an account of work sponsored by the United States Government. Neither the United States nor the United States Atomic Energy Commission, nor any of their employees, nor any of their contractors, subcontractors, or their employees, makes any warranty, express or implied, or assumes any legal liability or responsibility for the accuracy any pleteness or usefulness of any information, product or process disclosed, or represents that its would not infringe privately owned rights.
\end{abstract}




\section{DISCLAIMER}

This report was prepared as an account of work sponsored by an agency of the United States Government. Neither the United States Government nor any agency Thereof, nor any of their employees, makes any warranty, express or implied, or assumes any legal liability or responsibility for the accuracy, completeness, or usefulness of any information, apparatus, product, or process disclosed, or represents that its use would not infringe privately owned rights. Reference herein to any specific commercial product, process, or service by trade name, trademark, manufacturer, or otherwise does not necessarily constitute or imply its endorsement, recommendation, or favoring by the United States Government or any agency thereof. The views and opinions of authors expressed herein do not necessarily state or reflect those of the United States Government or any agency thereof. 


\section{DISCLAIMER}

Portions of this document may be illegible in electronic image products. Images are produced from the best available original document. 
AN ANALYTIC MODEL OF CYLINDRICAL METAL LINER COMPRESSION OF DT PLASMA

\author{
James W. Shearer \\ University of California, Lawrence Livermore Laboratory \\ Livermore, CA 94550 \\ June, 1974 .
}

\begin{abstract}
An analytical model is formulated to give an approximate description. of metal liner compression of DT-plasma (and magnetic field) in cylindrical. geometry. The model includes a correction for liner compression. Calculations are carried out for a copper liner. "Breakeven" conditions are found for a pure fusion system and for a hybrid system with a fission blanket. The results show that a pure fusion system requires gigajoules of energy per explosion, but the hybrid system needs only megajoules of energy per explosion.
\end{abstract}

\title{
I. INTRODUCTION
}

A well-known $(1,2)$ fusion energy proposal is the compression of deuterium-tritium plasma to thermonuclear temperatures by means of an implnding metallic liner. Experimental research programs based on this concept are in progress at Krasnaya Pakhra, USSR, $(3)$ and at the Naval Research Laboratory. (4)

In adition to computer studies, $(5,6)$ there has been some analytical work done on the concept. $(7,8,9,10)$ The purpose of this report is to construct an approximate analytical model of cylindrical liner compression of DT plasma which will permit evaluation of sizes and efficiencies for practical rystems. We vill concentrate our attention on the metal liner (including its compressional energy), and or. the DT plasma (including the magnetic field needed to insulate it from the walls). 


\section{PLASMA-FIELD MODEL}

The "plasma beta" $\beta$ is defined:

$$
\beta \equiv \frac{P_{p}}{P_{m p}}=\frac{16 \pi n k T}{B_{p}^{2}}
$$

where. $P_{p}=$ plasma pressure, $P_{m}=$ magnetic pressure inside the plasma and $B_{p}=$ corresponding axial magnetic field. T is the temperature of both electrons and ions. (assumed equal); $n$ is the density of either electrons or ions ( $z=1$ in a fully ionized DT plasma).

$$
\text { The "fill factor" } f_{f} \text { is defined: }
$$

$$
f_{f} \equiv \frac{A_{p}}{A_{t}}=\left(\frac{r_{p}}{r_{t}}\right)^{2}
$$

where $A_{p}$ is the area and $r_{p}$ is the radius of the plasma. $A_{t}$ and $r_{t}$ are the area and radius defined by the inner surface of the liner at turnaround.

Two possible plasma-liner configurations (at turnaround) are sketched in Fig. I. In the theta pinch case (Fig. Ia), one expects that the fill factor $f_{f}$ will be low because the $B_{z}$ magnetic field acts like a zerodensity fluid with $\gamma=2$ :

$$
\mathrm{P}_{\mathrm{I}} \sim \mathrm{B}_{\mathrm{Z}}^{2} \sim\left(\frac{\phi}{\mathrm{r}^{2}}\right)^{2} \sim \frac{1}{\mathrm{v}^{2}} \sim \frac{1}{\mathrm{v}^{\gamma}}
$$

where $\phi=$ flux, and $v=$ specific volume. Adiabatic compression of the plasma $(\gamma=5 / 3)$ leads to the proportionality:

$$
P \sim \frac{I}{v^{\gamma}} \cdot\left(\frac{I}{v}\right)^{5 / 3}
$$

Since $P_{m}=P_{p}$ throughout the Iiner compression, comparison of Eqs. (3) and (4) shows that the plasma volume will shrink relative to the field volume. Therefore, the fill factor $f_{f}$ will be low in this case, as stated.

The stabilized Z-pinch case (Fig. Ib) is different because the azimuthal $\mathrm{B}_{\theta}$ field varies more slowly with redius than either the axial 
field or the plasma. In the final, low radius limit, we have neglected it entirely, and filled the entire cavity with a low B plasmamaxial magnetic field mixture.

We now write down the plasma energy per unit length $E_{p}$ and magnetic field energy per unit length $\mathrm{E}_{\mathrm{m}}$ at turnaround:

$$
\begin{aligned}
& E_{p}=(3 n k T) f_{f} \pi r_{t}^{2} \\
& E_{m}=\left(B_{p}^{2} f_{f}+B_{m}^{2}\left(I-f_{f}\right)\right) \frac{r_{t}^{2}}{8}
\end{aligned}
$$

where $B_{m}$ is the axial magnetic field outside the plasma. The total pressure at turnaround, $P_{t}$, is:

$$
P_{t}=(2 n k T)\left(1+\frac{I}{B}\right)=B_{\cdot m}^{2} / 8 \pi
$$

Expressing the energies in terms of $P_{t}$ :

$$
\begin{aligned}
& E_{p}=\left(\frac{3}{2} \frac{\beta}{\beta+I} f_{f}\right)\left(\pi r_{t}^{2}\right) P_{t} \\
& E_{m}=\left(1-\frac{\beta}{\beta+I} f_{f}\right)\left(\pi r_{t}^{2}\right) P_{t}
\end{aligned}
$$

Finaliy, we remark that the pressure of the axial magnetic field requirës that either the plasma $\beta$. or the fill factor $f_{f}$ be low; therefore, the magnetic energy $F_{m}$ at turnaround will dominate the plasma energy $E_{p}$. The axial magnetic field is important because it suppresses instabilities, thermal conduction, and diffusion losses, (11) and it cannot easily be reduced. This is an inherent energy inefficiency of the liner compression system that must be taken into account.

\section{TURNAROUND DYIAMICS}

We consider the motion of the liner up to the time of turnaround, as shown in Fig. 2. We ignore the subsequent expansion, on the assumption 
that Rayleigh-Taylor instabilities on the inner surface of the liner will destroy the symetry at later times. (12) Assuming a thin, slow-moving liner:

$$
\ddot{r} \cong \frac{P}{\sigma}=\frac{P}{(\rho)(\Delta r)}
$$

where $r$ is the inner radius, $P$ is the pressure and $\sigma$ is the mass per unit area of the liner.

In cylindrical geometry the thin liner $\sigma$ will vary with the radius $r$ :

$$
\sigma=\sigma_{t} r_{t} / r
$$

where $\sigma_{t}, r_{t}$ are the respective values at turnaround time $(t=0$, as in Fig. 2).

Adiabatic compression in cylindrical geometry will vary as:

$$
P=P_{t}\left(\frac{v_{t}}{v}\right)^{\gamma}=P_{t}\left(\frac{r_{t}}{r}\right)^{2 r} \cong P_{t}\left(\frac{r_{t}}{r}\right)^{4}
$$

where we have chosen $\gamma=2$ as the best approximation for $\gamma$ near turnarvund. The rcason for this rhnire is the dominance of the axial magnetic field $B_{Z}$, as described in the last section.

Combining Eqs. (10); (11), and (12):

$$
\ddot{r}=\frac{P_{t} r_{t}^{3}}{\sigma_{t}} \frac{I}{r^{3}}
$$

The first integral of Eq. (13) is obtained from:

$$
\int_{u}^{0} u d u=\frac{P_{l} r_{t}^{3}}{\sigma_{t}} \int_{r}^{r} \frac{d r}{r^{3}}
$$

where $u=\dot{r}$, and $\ddot{r}=u(d u / d r)$. The result for the velocity. $u$ is:

$$
u=\frac{d r}{d t}=-\left(\frac{P_{t} r_{t}}{\sigma_{t}}\right)^{1 / 2}\left(i-\left(\frac{r_{t}}{r}\right)^{2}\right)^{1 / 2}
$$


The integration of Eq. (15) is accomplished with the substitution:

$$
\begin{aligned}
& x=\left(\frac{r}{r_{t}}\right)^{2}-I \quad d x=\frac{2 r d r}{r_{t}^{2}} \\
& -\int_{t}^{0 !} \frac{d t}{\tau_{t}}=\int_{\left(r / r_{t}\right)^{2}-1}^{0} \frac{d x}{2 x^{1 / 2}}
\end{aligned}
$$

where the characteristic time $\tau_{t}$ is defined by:

$$
\tau_{t} \equiv \sqrt{\frac{\sigma_{t} r_{t}}{P_{t}}}
$$

The final result is:

$$
\left(\frac{r}{r_{t}}\right)^{2}=1+\left(\frac{t}{\tau_{t}}\right)^{2}
$$

Equation (19) is the equation of a hyperbola in the r-t plane. For large values of $r$ and $t$, the velocity $u$ of the liner approaches $\left(r_{t} / \tau_{t}\right)$. This derivation is not exact because it ignores compressibility and thickness effects in the liner. $(7,9)$ However, in a later section wé will make an approximate correction for liner compressibility.

\section{IT NIST.FAR REACTIONS AT TURNAROUND}

The DT reaction energy yield Y (per unit length) is written, similar to Eqs. (8) and (9):

$$
Y=E_{D T}\left(\int_{-\infty}^{0} R_{D T} d t\right) \pi r_{t}^{2} f_{f}
$$

where $E_{D T}$ is the useful energy release per reaction, and where $R_{D T}$ is the reaction rate in the plasma per unit volume. Constant density is assumed, as $i r_{1}$ the configurations of $F i B$. 1. The reaction rate is written:

$$
\mathrm{R}_{\mathrm{DT}}=\mathrm{n}_{\mathrm{D}} \mathrm{n}_{\mathrm{T}} \overline{\sigma \mathrm{v}}(\mathrm{T})
$$

where $\mathrm{n}_{\mathrm{D}}=$ deuterium ion density, $\mathrm{n}_{\mathrm{T}}=$ tritium ion density, and $\overline{\sigma \mathrm{V}}(\mathrm{T})$ is the DT reaction cross section averaged over the lon velucity distribution, which is assuned to be Maxwellian at semperature $\mathrm{T}$ (keV). 
We will approximate $\overline{\sigma v}(T)$ by a square law fit which is accurate to about $20 \%$ in the temperature range $7 \mathrm{keV}<\mathrm{T}<20 \mathrm{keV}$ :

$$
\overline{\sigma v}(\mathrm{~T}) \cong 10^{-18} \mathrm{~T}^{2}
$$

where $\overline{\sigma v}$ is in $\mathrm{cm}^{3} / \mathrm{sec}$. Then, in a 50:50 DT mixture, the reaction rate is written:

$$
R_{D T}=2.5 \times 10^{-19}(\mathrm{nT})^{2}=\frac{\mathrm{P}_{\mathrm{p}}^{2}}{1.6 \times 10^{19} \mathrm{k}^{2}}
$$

where $n=n_{D}+n_{T}$ and where $k$ is Boltzmann's constant. But from Eqs. (7) and (12), we can substitute for the plasma pressure $P_{p}$, and obtain

$$
R_{D T}=\frac{I}{40.96}\left(\frac{\beta}{\beta+I} P_{t}\left(\frac{r_{t}}{r}\right)^{4}\right)^{2}=R_{t}\left(\frac{r_{t}}{r}\right)^{8} \text {. }
$$

where we have defined the maximum reaction rate $R_{t}$, and have substituted Boltzmann's constant $\mathrm{k}=1.6 \times 10^{-9} \mathrm{esu} / \mathrm{keV}$. In this approximation we have neglected the difference in the adiabatic $\gamma$. between the plasma and the field, but this neglect is consistent with Eq. (12).

Next we integrate the reaction rate over time by substituting Eq. (19) into Eq. (24)

(25) $\quad R_{t} \tau_{R} \equiv \int_{-\infty}^{0} R_{D N} d t=R_{t} \int_{0}^{\infty} \frac{d t}{\left(I+\left(t / \tau_{t}\right)^{2}\right)^{4}}$

where we have defined the effective reaction time $\tau_{R}$, and where the limits have been changed owing to the symmetry of the integral. If we make the substitution:

$$
u \equiv\left(\frac{t}{\tau_{t}}\right)^{2} \quad d u=\frac{2 t d t}{\tau_{t}^{2}}
$$


We obtain the beta function $B\left(\frac{1}{2}, \frac{7}{2}\right)$ :

(27)

$$
\tau_{R}=\frac{\tau_{t}}{2} \int_{0}^{\infty} \frac{u^{-1 / 2} d u}{(1+u)^{4}}=\frac{\tau_{2}}{2} B\left(\frac{1}{2}, \frac{7}{2}\right)
$$

$$
=\frac{\tau_{t}}{2} \frac{\Gamma\left(\frac{1}{2}\right) \Gamma\left(\frac{7}{2}\right)}{\Gamma(4)}=.491 \tau_{t}
$$

For convenience we will approximate:

$$
\tau_{R} \cong \frac{I}{2} \tau_{t}=\frac{I}{2}\left(\frac{\sigma_{t} r_{t}}{P_{t}}\right)^{1 / 2}
$$

Thus we have found that the effective reaction time constant $\tau_{R}$ is shorter than the dynamic time constant $\tau_{t}$ because of its steeper dependence on the radius $r$.

Now we substitute Eqs. (24), (25) and (28) back into Eq. (20), and we rind:

$$
\begin{aligned}
Y & =E_{D T} R_{t} \frac{\tau_{t}}{2} \pi r_{t}^{2} f_{f} \\
& \cong \frac{D T}{82}\left(\frac{\beta}{\beta+1}\right)^{2} f_{f}\left(\pi r_{t}^{2}\right) P_{t}^{2} \tau_{t}
\end{aligned}
$$

This equation for the DT reaction energy yield $Y$ can be directly compared to the input energies $E_{p}$ and $E_{n}$ (Eqs. (8)-(9)). For example, consider the "srientific breakeven" condition, that $\mathrm{Y}=\mathrm{E}_{\mathrm{p}}$; in that case we find, using $\mathrm{E}_{\mathrm{DT}}=17.6 \mathrm{MeV} /$ reaction:

$$
P(M B) \tau_{R}(\mu s e c) \cong 2.2 \frac{B+1}{\beta}
$$

where we have also used Eq. (28) for $\tau_{R^{*}}$. In the plasma temperuture range where we fit the cross section ( $\mathrm{Eq} .(2 ?))$, this corresponds to the Lawson criterion. ( 14 )

$$
4 \times 10^{13} \leqslant \mathrm{n \tau} \frac{\beta}{\beta+1} \leqslant 10^{14}
$$


Similar comparison can be made with the magnetic energy $E_{n}(E q \cdot(9))$, if desired.

These estimates assime that the percent burn is low compared to unity, and they ignore heating of the plasma by alpha particles and neutrons.

\section{COMPRESSIONAL ENERGY OF MEPAL LINER}

In addition to the adiabatic compressional energy imparted to the plasma and to the magnetic field, the liner also does work on itself:

$$
W=-\int_{v_{0}}^{v} P d v
$$

where $W$ is the work done per unit mass, $P$ is the pressure, $v$ is the specific volume $(\mathrm{cc} / \mathrm{gm})$, and $v_{0}$ is the STP value of the specific volume for the. metal of the liner.

Pressure versus volume curves for metals are well-known from both static and dynamic (high-explosive) experiments. (15) we shall not consider them in detail; rather, we shall make an algebraic fit to the data which is easily integrable in Eq. (32). By trial and error, we have found that the following exponential fit to the data gives simple analytical results:

$$
-\frac{\rho_{0}}{\rho} \equiv \frac{v}{v_{0}}=\sum_{i} a_{i} e^{-P / P_{i}}
$$

where $\mathrm{v} / \mathrm{v}_{0}$ is the specific volume ratio, and where the coefficients $a_{i}$ $P_{i}$ are fitted to the data. For example, the compressibility of copper $(15,16)$ in the pressure range $0-4.5 \mathrm{MB}$ is closely fitted by the equation:

$$
\left(\frac{v}{v_{0}}\right)_{C}=0.3 e^{-P / .65}+0.7 e^{-P / 15}
$$

where $P$ is the pressure in megabars. This f'it is illustrated in Fig. 3 . 
Using this simple fit, we first find the derivative:

$$
\frac{d v}{d P}=-\frac{1}{\rho_{0}} \sum_{i} \frac{a_{i}}{P_{i}} e^{-P / P_{i}}
$$

Then we integrate Eq. (32):

$$
\begin{aligned}
& W=-\int_{v_{0}}^{v} P \frac{d v}{d P} d P=+\frac{1}{\rho_{0}} \sum \frac{a_{i}}{P_{i}} \int_{0}^{P} P e^{-P / P_{i}} d P \\
& W=\frac{1}{\rho_{0}} \sum_{i} a_{i} P_{i}\left[1-\left(I+\frac{P}{P_{i}}\right) e^{-P / P_{i}}\right]
\end{aligned}
$$

Thus, we now have an approximate result for the liner compression.energy per gram.

In order to obtain an approximate pressure and compressional energy distribution for a thin, slow-moving liner (as previously assumed for Eq. (10)), it is most convenient to use the thickness parameter $n$ in units of mass per unit area:

$$
\mathrm{dn} \equiv \operatorname{pdr}
$$

At the outside radius of the liner, we define $\eta \equiv 0$. Then at the inside radius at. tumnarnima time, we have:

(38) $\quad \sigma_{t}=\int_{0}^{\sigma_{t}} \mathrm{dn}=\int_{r_{t+\Delta}}^{r_{t}} . \mathrm{dr}$

where $\Delta$ is the liner thickness (See Jig. 2), and wherc $\sigma_{t}$ is the liner mass per unit area introduced in Eqs. (10)-(11). The pressure distribution is then obtained by means of the impulse-momentum theorem:

$$
\int P d t=P \tau_{t}=n u_{0}
$$

where $u_{0}$ is the velocity at an early time, long before turnaround. Remembering that $P=P_{t}$ when $n=\sigma_{t}$, we write:

$$
P=P_{t} \frac{\eta}{\sigma}
$$


See Fig. 4. This formula for the pressure distribution $P$ neglects the inertia of the plasma, convergence effects in thick liners, and liner heating. However, it should be a good first approximation for the purpose of estimating the compressional energy $0 \vec{i}$ the liner.

The liner compression energy $E_{L}$ per unit length at turnaround time is now found by integration:

$$
\mathrm{E}_{L}=\int_{0}^{\sigma_{t}} 2 \pi r_{t} W d n
$$

Substitution of Eq. (36) leads to:

$$
E_{L}=2 \pi \frac{r_{t}}{\rho_{0}} \sum_{i} a_{i} P_{i} \int_{0}^{\sigma_{t}}\left(1-\left(1+\alpha_{i} n\right) e^{-\alpha_{i} n}\right) d n
$$

where the parameter $\alpha_{i}$ is defined by:

$$
\alpha_{i} \equiv P_{t} / \sigma_{t} P_{i}
$$

After carrying out the integration, one obtains:

$$
F_{L}=2 \pi \frac{r_{t} \sigma_{t}}{\rho_{0}} Y\left(P_{t}\right)
$$

where the function $Y(P)$ is defined:

$$
Y(P) \equiv \sum_{i} a_{i} P_{i}\left\{\left(e^{-P / P} i+1\right)+2 \cdot \frac{P}{P}\left(e^{-P / P} i-1\right)\right\}
$$

This is the expression for the liner energy which we sought.

In order to compare the liner energy $E_{L}(E q .(44))$ with the other energies in thie system (Eqs. (8), (9), and (29)), it is convenient to rewrite it in the following way:

$$
E_{L}=\left(\pi r_{t}^{2}\right) P_{t}\left(\frac{2 \sigma}{\rho_{0} r_{t} P_{t}}\right) Y\left(\underline{P}_{t}\right)
$$

It is also convenient to express the liner thickness $\Lambda$ at turntround as 
a multiple of the turnaround radius $r_{t}$ (See Fig. ?).

$$
\Delta \equiv f_{L} r_{t}=\int_{r_{t}}^{r_{t}+\Delta} d r
$$

We wish to know how $\Delta$ and $f_{L}$ vary with the pressure $P_{t}$; to find this we must again integrate through the layer:

$$
\frac{d r}{d \eta}=v=\frac{1}{\rho_{0}} \sum_{i} a_{i} e^{-\alpha_{i} n}
$$

where we have used Eqs. (33), (37), and (40). Combining Eqs. (47) and (48), and carrying out the integration, one obtains:

$$
\Delta=f_{L} r_{t}=\frac{\sigma_{t}}{\rho_{0}} \mathrm{Z}\left(\mathrm{P}_{t}\right)
$$

where the function $Z(P)$ is defined:

$$
z(P) \equiv \sum_{i} a_{i} \frac{P_{i}}{P_{t}}\left(1-e^{-P_{t} / P_{i}}\right)
$$

Substitution back into Eq. (46) gives us the following form for liner enerey:

$$
E_{L}=\left(\pi r_{t}^{2} P_{t}\right)\left(f_{L}\right)\left(S\left(P_{t}\right)\right)
$$

where the function $S(P)$ is defined:

$$
S(P) \equiv 2 Y(P) / P Z(P)
$$

The function $\mathrm{S}(\mathrm{P})$ can be calculated for any particular liner metal. In particular for the copper fit. (Eq. (34)), one calculates the results shown in Fig. 
VI. FORMULATION OF RADIAL SYSTEM SCALING RELATIONS

We are now ready to consider the total system of liner, plasma, magnetic field, and DT reactions. We define the overall energy multiplication:

$$
M \equiv \frac{Y}{E_{P}+E_{M}+E_{L}}=\frac{\frac{E_{D T}}{82}\left(\frac{\beta}{\beta+1}\right)^{2} \hat{f}_{f} P_{t} \tau_{t}}{1+\frac{1}{2} \frac{\beta}{\beta+1} f_{f}+f_{L} S\left(P_{t}\right)}
$$

where we have used Eqs. (8), (9), (29), and (5l). This equation can be solved for the impulse product $\mathrm{P}_{t}(\mathrm{MB}) \tau_{t}$ ( $\left.\mu \mathrm{sec}\right)$ :

$$
P_{t} \tau_{t}=2.91\left(\frac{B+I}{B}\right)^{2}\left(\frac{M}{f_{f}}\right)\left(I+\frac{I}{2} \frac{B}{B+I} f_{f}+f_{L} S\left(P_{t}^{j}\right)\right)
$$

where we regard the turnaround pressure $P_{t}(M B)$ as the independent variable, and $B, f_{f}, f_{L}$, and $M$ as parameters of the model.

Equation (54) is consistent with Eq. (30), which was solved for the special case $B \rightarrow \infty, f_{f}=1, M=I$, and negligible compressibility. Two other incompressible liner cases of interest are models (a) and (b) of Fig. 1. In model (a), where the plasma is not mixed with the field, we obtain

(55)

$$
\left(P_{t} \tau_{t}\right)_{a} \cong 13 M \quad M b-\mu \mathrm{sec}
$$

where the liner is incompressible ( $E_{L}$ negligible). . With the same assumptions, the mixed plasma and field case (model (b)), gives the result

$$
\left(P_{t} \tau_{t}\right)_{b} \cong 52 \mathrm{M} . \mathrm{Mb}-\mu \mathrm{sec}
$$

which is a factor of four higher. Note that in these two cases the last factor in Eq. (54) was the same number. The::e cases show that for pulsed systems it is better to try to keep the plasma from mixing with the field, when one wishes to achieve high values of energy multiplication $M_{0}$. The reason for this is the quadratic density dependence of the nuclear reaction (Eq. (2l)). 
In order to apply Eq.'(54). to specific examples, one uses the solution for $P_{t} \tau_{t}$ to solve for the radius $r_{t}$ :

$$
\dot{r}_{t}=P_{t} \tau_{t}\left(\frac{Z\left(P_{t}\right)}{P_{t} f_{I}}\right)^{I / 2}
$$

which can be derived from Eqs. (18) and (49). One proceeds from there to find the energies (per unit length) $E_{p}(E q .(8)), E_{M}(E q .(9))$, and $E_{L}$ (Eq. (51). The yield Y can be found either from Eq. (29)), or by multiplying $M$ into the sum $E_{P}+E_{M}+E_{L}$.

Another parameter of interest is the liner mass per unit length $\mathrm{M}_{\mathrm{L}}$ :

$$
M_{L}=2 \pi r_{t} \sigma_{t}=2 \pi \frac{\left(P_{t} r_{t}\right)^{2}}{P_{t}}
$$

where we have used Eq. (18). Let us assume that the sum of plasma, magnetic, and liner energies was originally entirely kinetic energy of the liner - this assumption ignores plasma preheat and initial magnetic field energy. In that case, we can find the initial liner velocity $u_{\perp}$ :

$$
u_{L}=\left\{\frac{2}{M_{L}}\left(E_{P}+E_{M}+E_{L}\right)\right\}^{I / 2}
$$

This velonity is important when considering liner acceleration methods.

\section{- VII. AN APPROXIMATE AXIAL SYSTEM SCALING RELATION}

The necessary $I_{P}$ of the long hot plasma column depends on the time it takes for the plasma to escape out the ends. This time must be greater than the reaction time $\tau_{R}$; thus we have:

$$
I_{P} \geq v_{a} \tau_{R}
$$

where $v_{a}$ is the acoustic velocity of the plasma." A number of analyses of this end loss problem have been made in connection with liner theta pinch studies; three of these are cited in the references. $(17,18,19)$ A number of proposals for shortening this length have been made, such as multiple mirrors, (17) or cusp geometry terminations. (20) 
For the purposes of this report, we will adopt the arbitrary criterion that the length $\mathrm{L}_{\mathrm{P}}$ can be simply scaled according to the equation:

$$
L_{P}(\text { meters }) \cong \frac{10^{20}}{n} M \cong \frac{3.2}{P_{t}(\mathrm{MB})} M
$$

where we have put $T=10 \mathrm{KeV}$, and where the reaction time $\tau_{R}$ varies linearly with $M$, and inversely with $P_{t}$. In the density range $10^{16}<{ }^{2}<10^{18}$, this criterion agrees with the estimates of the references $(17,18,19)$ within a factor of 2. In the lower density range the $\sim .1 \mathrm{~km}$ length has thus far daunted any serious attempt to build a reactor-size theta pinch. However, at the densities considered here, the length is much shørter.

\section{VIII. "LINER BRFAKEVEN" DT FUSION CALCULATIONS FOR COPPER IINER}

We define "Iiner breakeven" as the condition that $M=1$ (see Eq. (53)); this is a more stringent condition than "scientific breakeven" (Eq. (30)). We shall choose model (a) of Fig. I as our plasma configuration, and we shall use a copper liner, as modeled by Eq. (34). Under these conditions the impulse product (Eq. (54)) reduces to:

$$
P_{t}(M B) \tau_{t}(\text { usec })=13.1\left(1+\frac{8}{9} f_{L} S\left(P_{t}\right)\right)
$$

where $E\left(F_{t}\right)$ is given in $E q .(52)$ and Fig. 5.

In Figs. 6-8 we present various parameters for the breakeven system, using Eqs. (57)-(62). One finds that at low pressures the inner liner radius $r_{t}$ is large, implying a large bulky system. on the other hand, at high pressures the initial velocity $u_{L}$ is large; in fact, it is greater than the velocities one would expect even from a liner driven by TNT. (16)

In Figs. $\%$ and 8 we find that the initial liner kinetic energy is very larefe over the entire pressure range. Using a rough figure of 5 megajoules per kilogram for the energy release from TNT, we see that the total energy is equivalent to in $400 \mathrm{~kg}$ of TNT at $P=I \mathrm{MB}$, and $\simeq 25 \mathrm{~kg}$ of TNT at $\mathrm{P}=20 \mathrm{MB}$. Thus, the low pressure systems require very large 
containment vessels. The high pressure systems, as remarked before, require very high velocity $u_{L}$ (Fig. 6).

It is possible to conceive of systems at lower pressure $(P<I M B)$, that use thicker liners $\left(f_{L}>2\right)$. However, this analytical nodel is based on the assumption of comparatively thin liners, and thick liners might better be analyzed by the method of Robson. ( 7 ) In addition, such lower pressure systems would have to be many meters long in order to prevent prohibitive end Iosses (see Eq. (6I)).

It would be possible to obtain almost nine times lower total energy results for a plasma model in which the fill factor $f_{f}$ is raised from $1 / 4$ to $3 / 4$ (see Eq. (54)). However, it would be much harder to obtain such a fill factor, in practice, particularly at the end of the liner compression. Thus, it is felt that the chosen example is more realistic.

The effect of the liner compressional energy is most prominent at high pressure. In fact, this is the reason that the thicker liner curve $\left(f_{L}=2\right)$ crosses over the thinner liner curve $\left(f_{L}=1\right)$ near $17 . M B$ in Figs. 7-8.

Finally, it should be emphasized that even these large, high energy systems will not be large enough for a working fusion energy extraction system. Inefficiencies in the liner propulsion system, ${ }^{(10)}$ and the necessity to produce' a surplus of useful power dictate the requirement that the overall liner multiplication $M$ should be at least $5-10$. But inspection of Eqs. (8), (9), (29), (51), (54), (57), and (61) shows that: $r_{t}$ and $I_{P}$ scale as $M ; E_{P}, F_{M}$, and $E_{L}$ scale as $M^{2}$; and $Y$ scales as $M^{3}$. The total energy input scales as $M^{3}$, and the total yield scales as $M^{4}$.

These total energy scaling factors are apparently true for any threedimensional inertial system - they have already been show to be true for 
spherical deuterium pellets. (2l) Future attempts to create a more practical system for fusion power by the liner method will have to find some way to overcome this difficulty that low pressure systems require enormous sizes and energies.

\section{FUSION LINER COMBINED WITH FISSIONABLE BLANKET}

In computing the energy yield of a pure fusion D-T liner contained explosion, we used the energy value $\mathrm{E}_{\mathrm{DT}}=17.6 \mathrm{MeV} /$ reaction (see Eqs. (29) $-(30)$ ). It was assumed that most of this energy reached a neutronabsorbing blanket outside of the containment vessel (see Fig. 9). Although the alpha particles would not reach the blanket, there is additional compensatory energy released in the blanket by the $\mathrm{n} \gamma$ capture reaction. Let us now consider the energy situation where the blanket contains a considerable amount of fissionable material.

We assume that the fissionable material is nowhere near the amount needed for a critical assembly, but that there is sufficient neutron multiplication (by nan and nf reactions) to have, on the average, ope fission reaction in the blanket for every $14 \mathrm{MeV}$ neutron produced by the Iinercompressed DT plasma. However, remember that the energy release per fission is more than ten times the energy release per DT reaction. Therefore, for this example, overall system energy breakeven is reached when the fusion multiplication parameter $M=0.1$, or one tenth its value for the previous example.

But from the remarks on scaling just given in the previous section, we see that changing $M$ from 1.0 to 0.1 will have profound effects on the system size. To show this we have replotted the parameters of the previous example for the case $M=0.1$; see Fig. 10 . We find that the total energy per pulse in this system is less tha:l 1 kilogram of TNT equivalent an energy which is much more accessible to common engineering containment practice.

Hybrid fusion-fission systems have previously been discussed, (22) but not in conbination with an inertially contained I'l' tusion source. 
From the point of view of liner applications, these results suggest that such a hybrid system is a much more achievable goal than a pure fusion reactor.

\section{COMPARISONS WITH OTHER WORK}

This analysis is in qualitative agreement with some recent computer calculations, which have been done on the IASNEX code. (6) The comparison is not exact because most of the computer calculations used thicker liners and different fill factors. For these conditions the computer runs gave a DT fusion breakeven level for thick copper liners of 90 megajoules/meter. The analytical results for thinner liners at breakeven were from $500-800$ megajoules/meter (see Fig. 7). Some computer runs using thinner liners at 90 megajoules/meter did not reach breakeven, in agreement with the results of the analysis.

More exact comparisons could be made by means of Eq. (53) - choosing $B, f_{f}, f_{L}, P_{t}$, and $\tau_{t}$ from a computer run and comparing the calculated value of $M$ (or $Y$ ) with the computed one. This has not yet been done. 


\section{REFERENCES}

(1) J. Go Linhart, "Plasma and Megagauss. Fields", pp 387-396 of "Proceedings of the Conference on Megagauss Magnetic Field Generation by Explosives and Related Experiments", ed. by H. Knoepfe]. and F. Herlach, EUR 2750.e, Euratom, Brussels, (1966).

(2) E. Velikhov, Proceedings of the Fifth European Conference on Controlled Fusion and Plasma Physics (Grenoble, August, 1972).

(3) R. A. Shannyy, private communication.

(4) P. J. Turchi, private communication.

(5) Jay P. Boris, Ramy A. Shanny, and N. K. Winsor, "Generation of a Fusion Plasma in the LINUS O-Pinch", Bulletin of the American Physical Society 17, No. 11, 1029 (Nov. 1972).

(6) William C. Condit, "A Parameter Study of $\mathrm{B}_{\mathrm{Z}}$ Liner Implosions for Possible CTR Applications", Univ. of Calif. Lawrence Livermore Lab. Report UCID-16474 (Jar.. 1974 ).

(7) A. E. Robson, "Fundamental Requirements of a Fusion Feasibility Experiment Based on Flux Compression by a Collapsing Liner", NRL Memorandum Report 2616, Naval Research Lab., Washington, D, .. (July, 1973).

(8) A. E. Robson, "The Flying Cusp: A Compact Pulsed Fusion System", NRL Memorandum Report 2692; Naval Research Lab., Washington, D.C. (Dec. Is?

(9) P. J. Turchi, "Spherical Implosion of Thick Liners with Compressibility and Plasma Loss", NRL Memorandum Report 271I, Naval Research Lab., Washington, D.C.・(Jan. 1974$)$.

(10) James W. Shearer, "The Theta Field Liner Concept", Univ. of Calif. Lawrence Livermore Laboratory Report UCID-164I6 (Dec. 1973). 
(11) Lyman Spitzer, Jr., "Physics of Fully Ionized Gases" and ed., Interscience, New York (1962).

(12) D. L. Book and N. K. Winsor, "Rotational Stabilization in Axial Flux Compression Experiments", NRL Memorandum Report 2643, Naval Research Lab., Washington, D.C. (Nov. 1973).

(13) NBS Handbook of Mathematical Functions, ed. by Milton Abramowitz and Irene A. Stegun, Dover Publications, New York (1968), pp 258-272.

(14) J. D. Lawson, "Some Criteria for a Power Producing Thermonuclear Reactor", Proc. of the Phys. Soc. of London, Sec. B, 70, 6-10 (1957).

(15) R. Norris Keeler, "High Pressure Compressibilities", pages 4-96 - 4-104. in "American Institute of Physics Handbook", 3rd edition, ed. by Dwight E. Gray and Mark W. Zemansky, McGraw-Hill, New York (1972).

(16) R. G. McQueen and S. P. Marsh, "Equation of State for Nineteen Metallic Elements from Shock-Wave Measurements to Two Megabars", J. of Appl. Phys. 31, 1253-1269 (July, 2960).

(17) John M. Dawson, Abraham Hertzberg, George C. Vlases, Harlow G. Ahlstrom, Loren C. Steinhauer, Ray E. Kidder, and W. L. Kruer, "Controlled Fusion Using Long Wavelength Laser Heating with Magnetic Confinement", to appear in "Fundamental and Applied Laser Physics", ed. by M. S. Feld, A. Javan, and N. A. Kurnit, Wiley, New York (1973).

(18) Richard L. Morse, "Electron Temperature and Thermal Conduction in HighEnergy $\theta$ Pinches", Physies of Fluids 16, 545-549 (April, 1973).

(19) W. Koppendorfer, W. Schneider, and J. Sommer, "Conclusions on Linear Reactor Devices from Theoretical and Experimental Investigations of End Losses from Theta Pinch Plasmas", 5th European Conference on Controlled Fusion and Plasma Physics, 21-25, August 1972, Grenoble, France.' 
(20) $\therefore$. E. Robson, private communication.

(21) $\because$ E. Kidder, "Some Aspects of Controlled Fusion by Use of Lasers", $\because$ appear in "Fundamental and Applied Laser Physics", ed. by M. S. irlda, A. Javan, and N. A. Kurnit, Wiley, New York (1973).

(22) $\therefore$. D. Lee, "Neutronics of Subcritical Fast Fission Blankets for D-T ;"usion Reactors", Univ. of Calif. Lawrence Livermore Laboratory i'sport UCRL-73952 (June, 1972). 

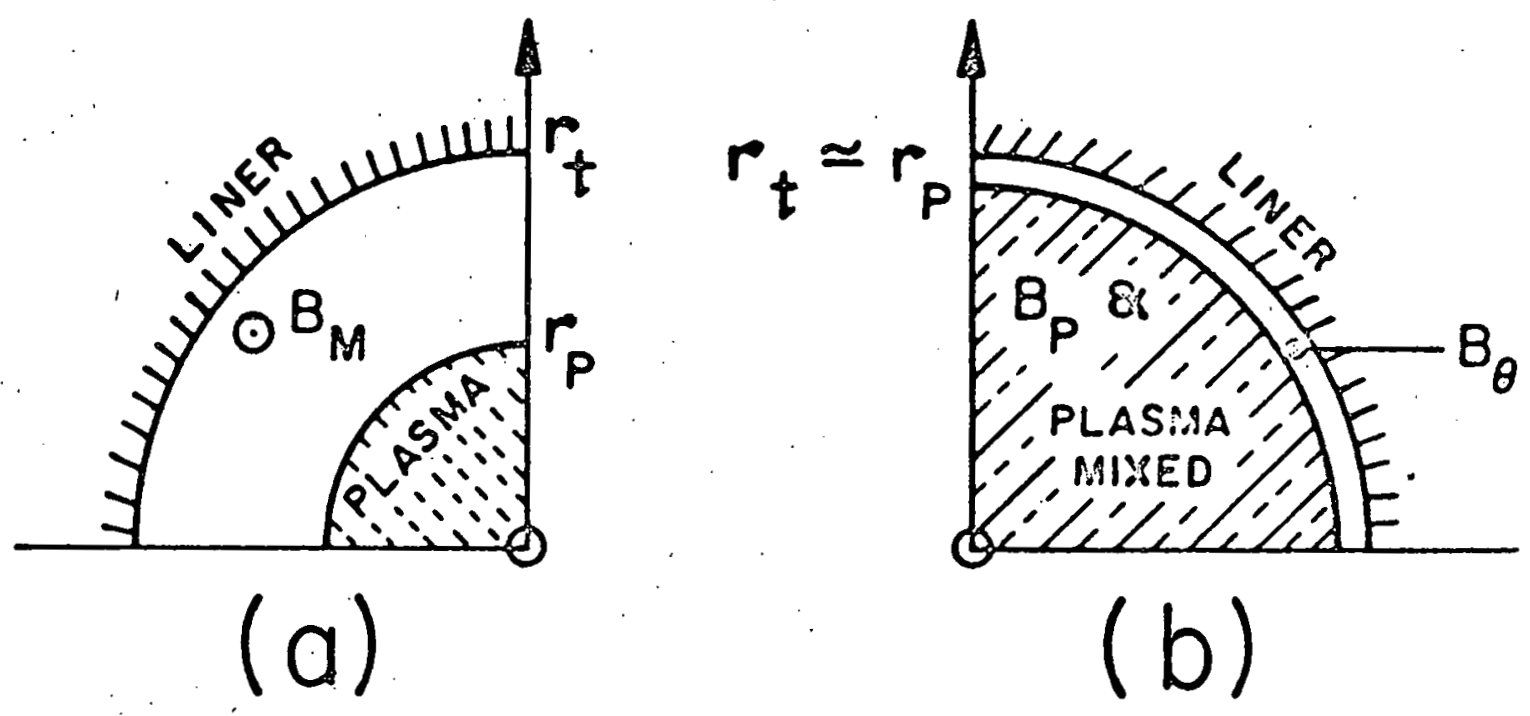

Figure ?

Two extreme models of possible plasma-liner configurations: (a) A theta plruch with no magnetic İield dittiused into the plasma, (b) A stabilized Z-pinch with axial magnetic field and plasma mixed. In terms of Eqs. (I) and (2) we have:

$\begin{array}{ccc}\text { Model } & \underline{B} & \frac{f_{f}}{1 / 4} \\ \text { (a) } & \infty & 1 / 4 \\ \text { (b) } & 1 / 3 & 1 \\ \text { Field only } & 0 & 1\end{array}$




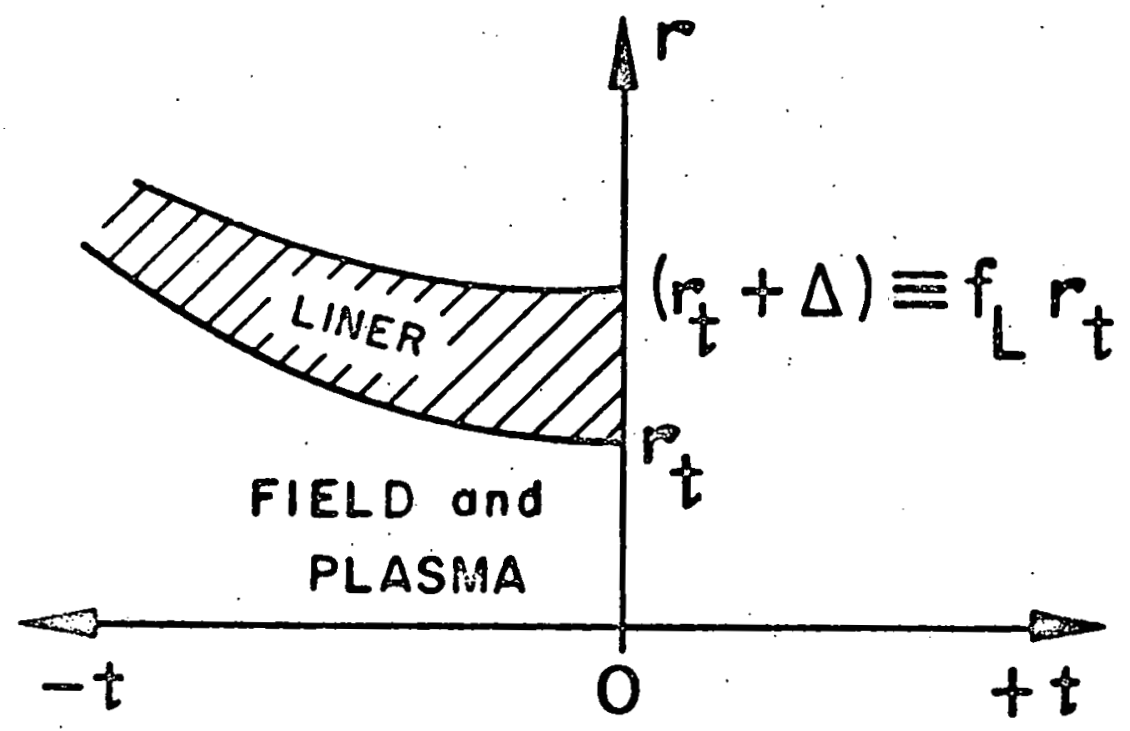

Figure ?

Radius $r$ versus time $t$ plot of the "turnaround" geometry of liner and plasma. 


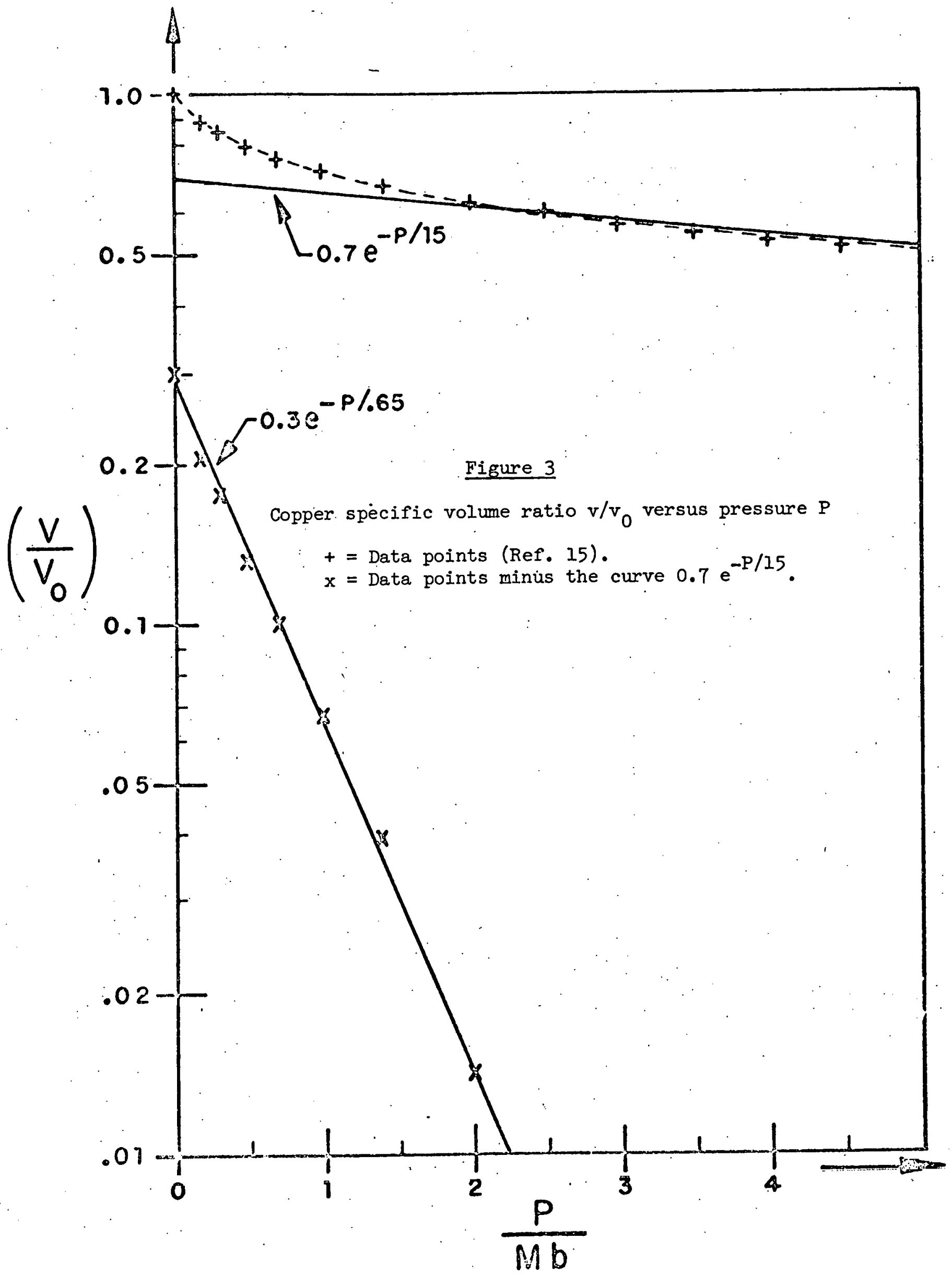




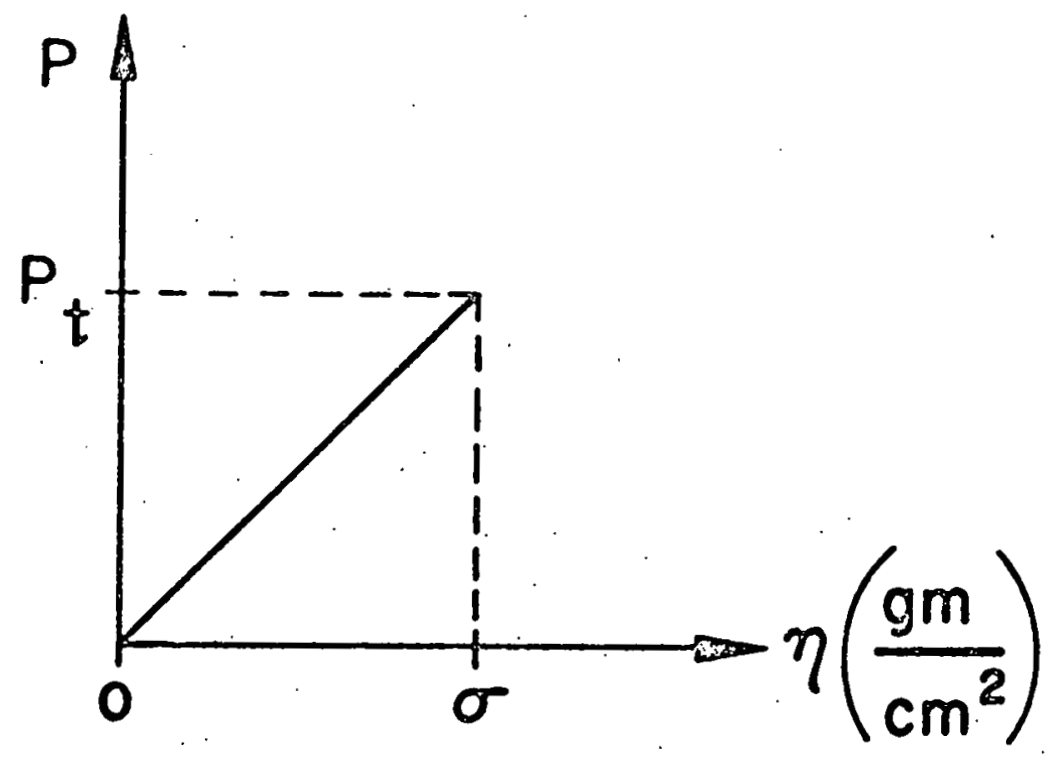

Figure 4

Liner pressure distribution as a function
the parameter $n$, where $n=\int_{r_{t}+\delta}^{r} \rho d r$




\section{Figure 5}

Compression functions for copper (Eqs. 34, 45, 50, and 52). Dotted lines are an extrapolation beyond the pressures tabulated in Ref. 1.5:
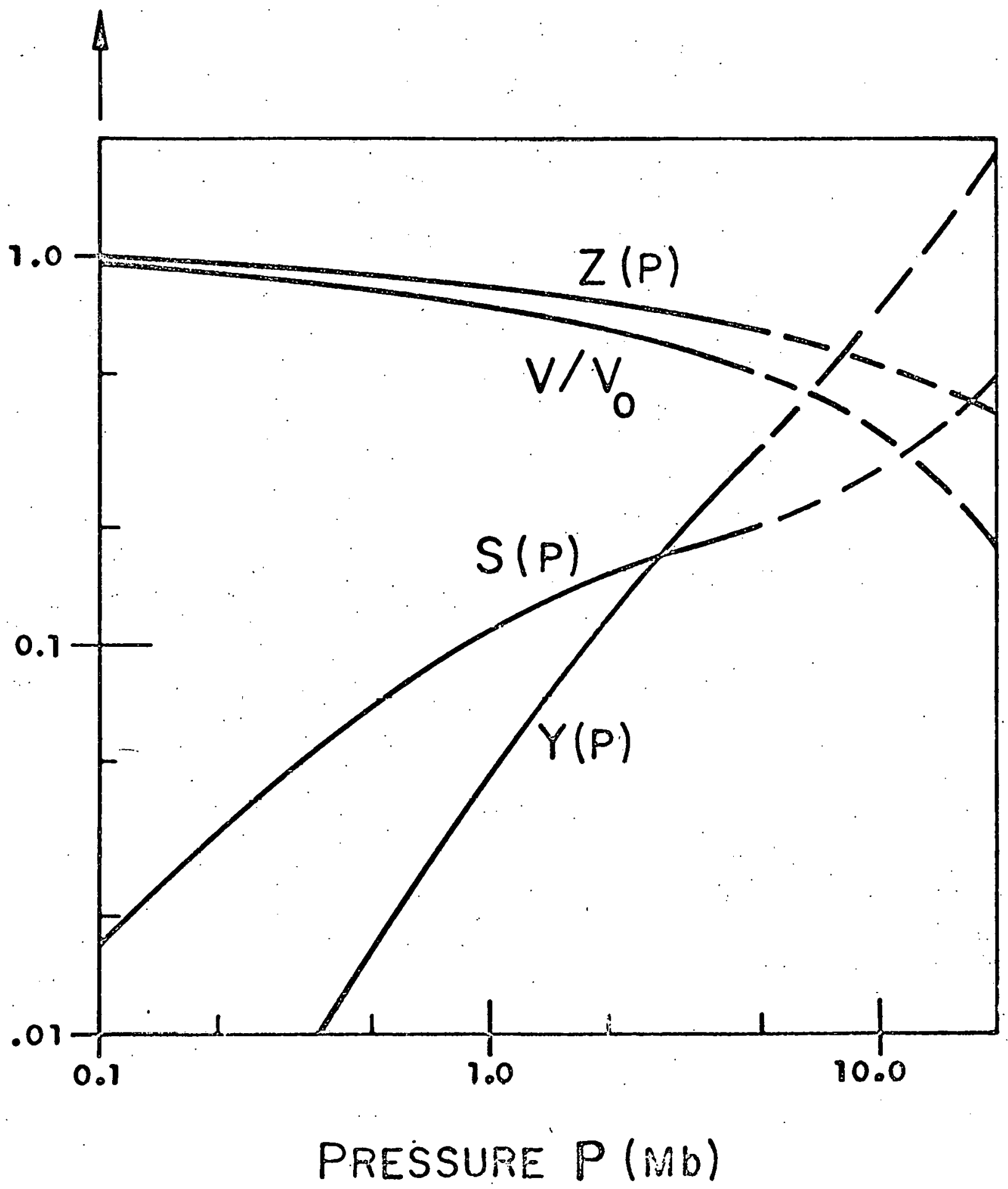
$-27-$

Figure 6

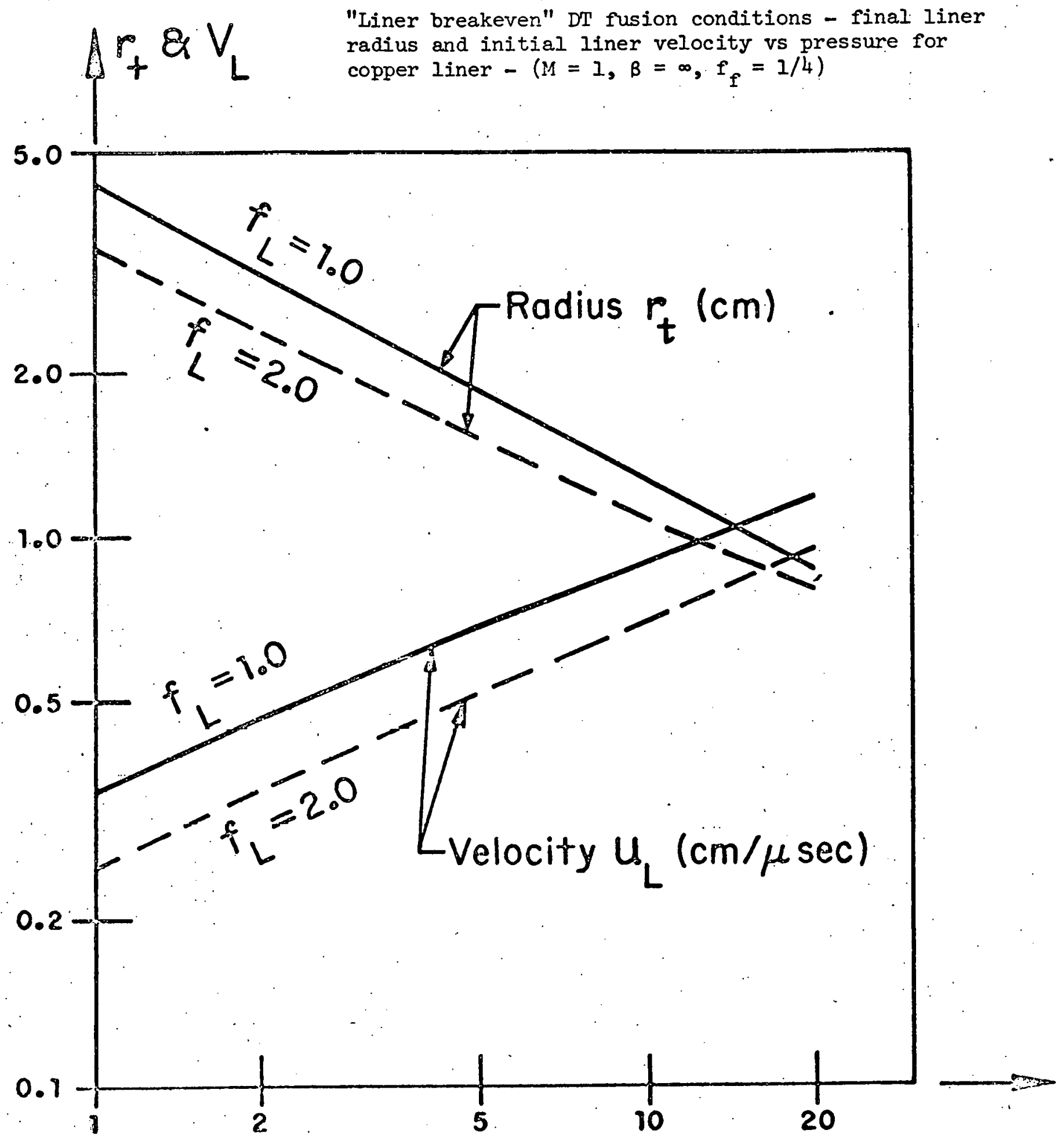

$$
\text { PRESSURE } P_{t}(M b)
$$




\section{Fizure 7}

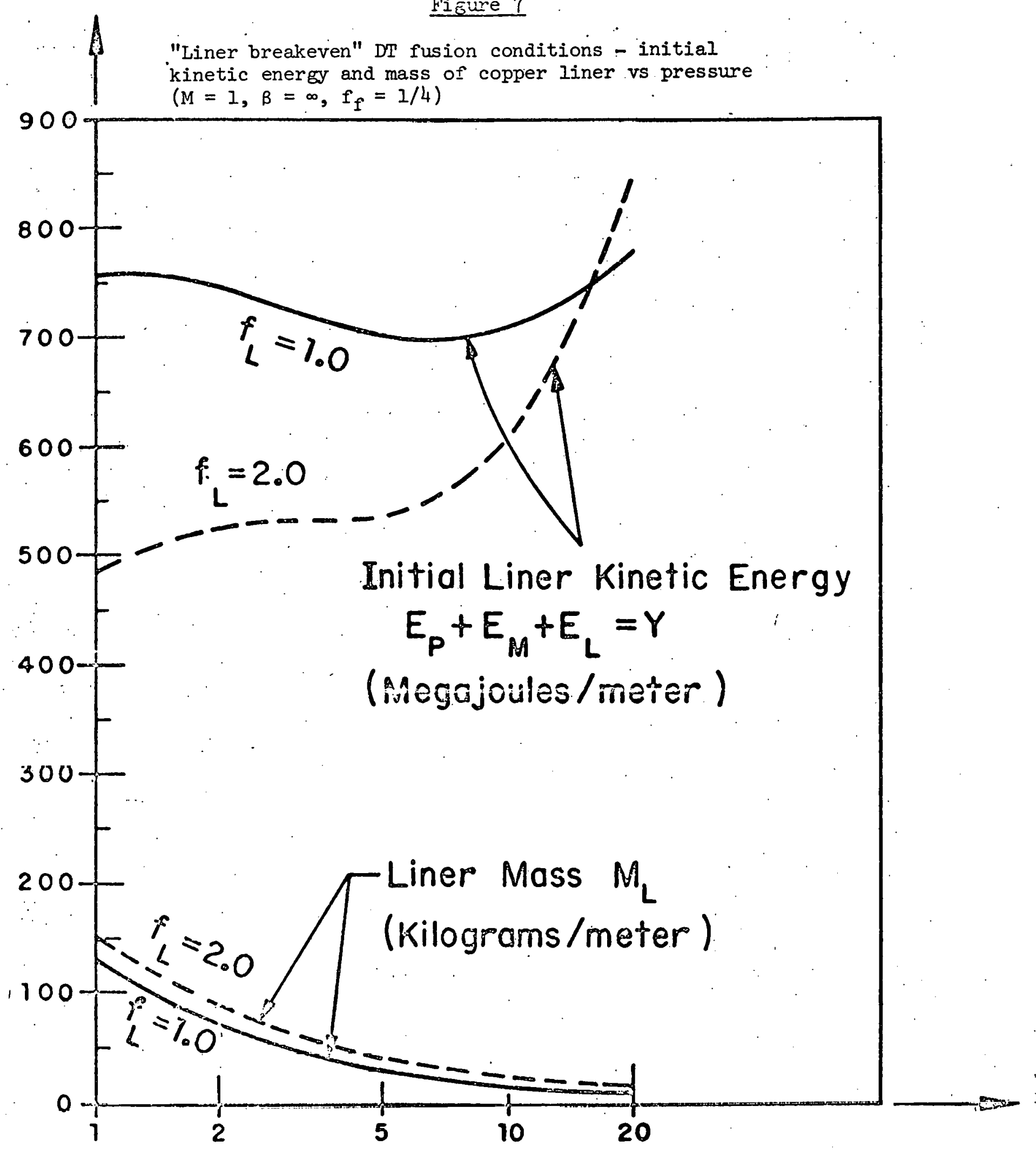

PRESSURE $P_{t}(\mathrm{Mb})$ 
Figure 8

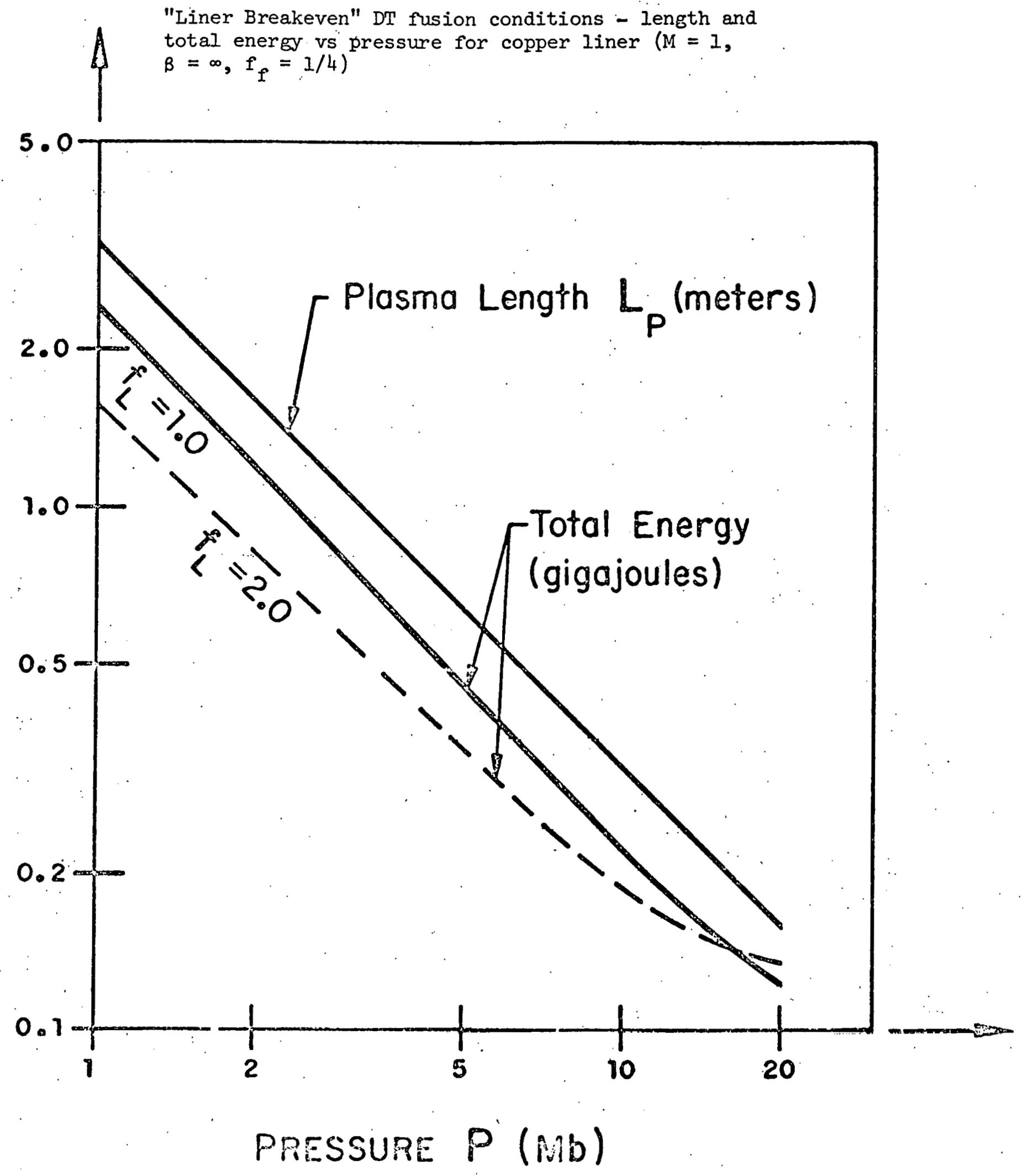


Figure 9

Overall Liner Reactor Schematic

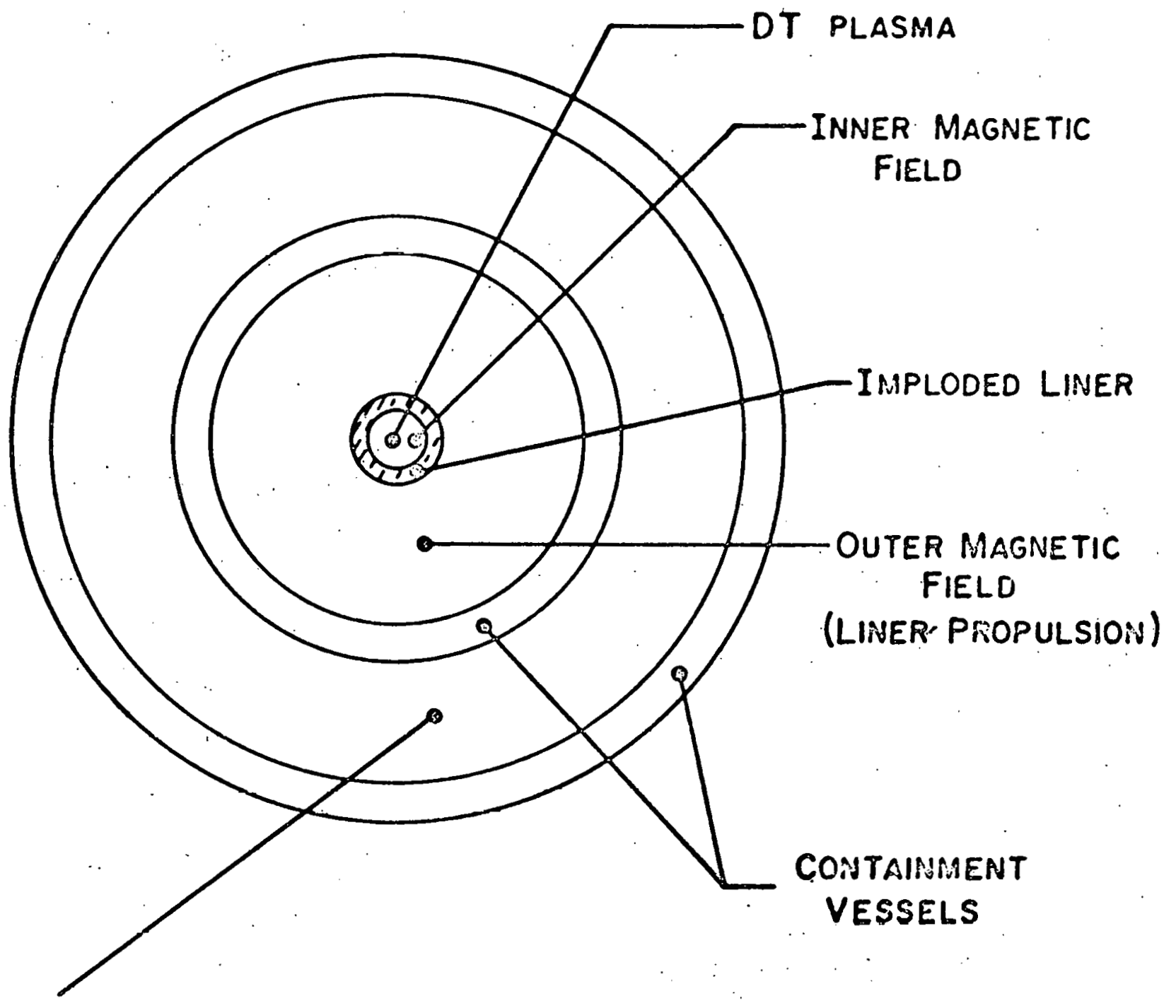

BLANKET - for a pure DT fusion system this is liquid

lithium, which acts as both a heat exchanger and a tritium regenerator - for a hybrid system this would be a mixture of lithium and fissionable mate:ial. 


\section{Figure 10}

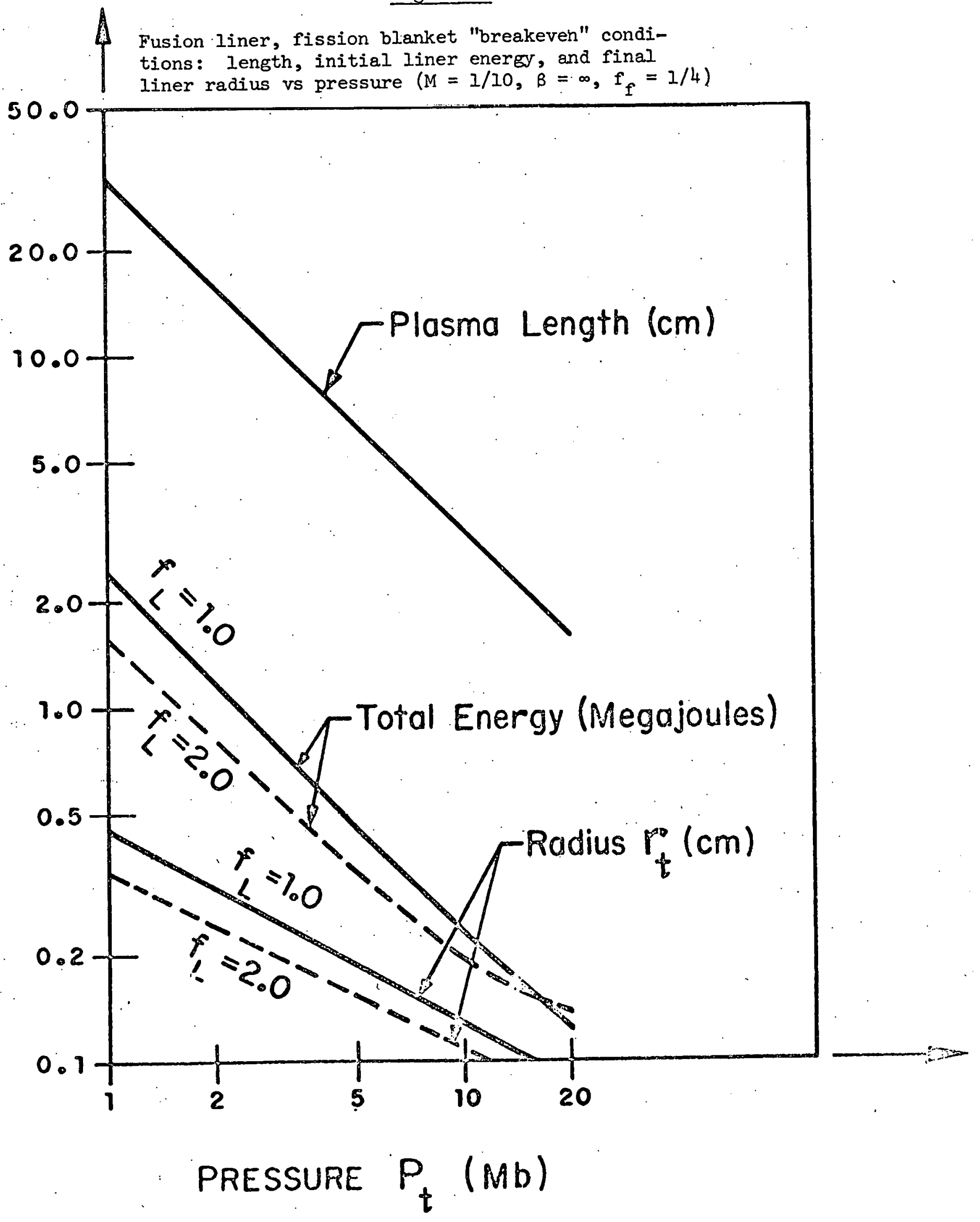




\section{DISTRIBUTION}

\section{External}

Dr. A. E. Robson

Dr. R. A. Shanny

Dr. P. J. Turchi

Naval Research Laboratory

Washington, D.C. 20390

Dr. C. M. Fowler

Los Alamos Scientific Laboratory

Los Alamos, New Mexico 87544

Prof. Abraham Herzberg

College of Engineering

Aerospace Research Laboratory

University of Washington

Seattle, Washington 98105

Dr. Stanley Humphries

Lab. for Plasma Studies Upson Hall

Cornell University

Ithaca, New York 14850
Internal

S. E. Bodner $(\mathrm{A} / \mathrm{I}-32)$

R. J. Briggs (M/I-382)

W. P. Chandler $(A / L-80)$

J. C. Clark (EE/I-153)

W. C. Condit $(A / I-80)$

T. J. Fessenden (M/L-382)

T. K. Forler $(M / L-382)$

E. K. Freytag (EE/L-153)

E. Garelis (A/L-80)

R. L. Gullickson (T/I-7I)

C. W. Hartman (M/I-387)

R. N: Keeler $(T / L-7 I)$

R. E. Kidder $(T / I-7 I)$

W. I. Kruer $(A / I-32)$

W. A. Lokke $(A / I-33)$

J. K. Landauer $(A / L-33)$

J. S. Luce $(T / L-7 I)$

G. Maenchen $(A / L-80)$

D. J. Meeker $(A / L-80)$

G. Moses (A/L-80)

P. Moulthrop (Nuclear Explosives/L-2l)

D. A. Nowak $(A / L-80)$

J. H. Nuckolls $(A / I-32)$

J. S. Pettibone (A/I-80)

H. L. Reynolds (Nuclear Explosives/I-2I)

H. L. Sahlin (T/L-TI)

J. W. Shearer $(10)(A / I-80)$

E. Teller. (Physics/I-0)

J. G. Vidal (T/I $-7 I)$

T. Wainwright (T/L-71)

P. C. Wheeler $(A / L-34)$

J. R. Wilson $(B / L-24)$

TID Files (5) ( L -9 )

"This report was prepared as an account of work sponsored by the United States Goverument: Neithur the United Stutes nor the United States Atomic Energy Corronission. nor any of their the United States Atomic Energy Corronission, nor any of their employess, mukes any warranty. express or implied, or ussumes any legal liability or respunsibitity for the aceuracy. complotencs or usefulness of any infornation appar itus, product or ptocess disclosed, or represents that its use would not infringe privatslyowned rightș." 